\title{
ASPECTOS DE CONTAMINAÇÃo BIOLÓGICA EM FILTROS DE CONDICIONADORES DE AR INSTALADOS EM DOMICÍLIOS DA CIDADE de MANAUS - AM
}

\section{ASPECTS OF BIOLOGICAL CONTAMINATION IN AIR CONDITIONING FILTERS INSTALLED IN MANAUS CITY HOUSES (AM)}

\section{ELIZABETH FERREIRA CARTAXO}

Professora Doutora da Universidade Federal do Amazonas - UFAM, Faculdade de Tecnologia. Doutora em

Planejamento Energético. Coordenadora do Núcleo Interdisciplinar de Energia Meio Ambiente e Água - NIEMA

\section{Ana Catarina Lima Chaves Gonçalves}

Lic. Biologia. MSc. Ciências do Ambiente e da Sustentabilidade na Amazônia

\section{FABRÍCIO RodRIGUES Costa \\ Engenheiro Eletricista}

\section{ILSA MARIA VALOIS COELHO}

\begin{abstract}
Mestranda em "Ciências do Ambiente e Sustentabilidade da Amazônia" na Universidade Federal do Amazonas - UFAM. Especialista em "Metodologia do Ensino Superior". Pesquisadora do Núcleo Interdisciplinar de Energia, Meio Ambiente e Água - Faculdade de Tecnologia da UFAM
\end{abstract}

\section{JANUÁRIO GAMA DOS SANTOS}

MSc. Ciências dos Alimentos - Microbiologia. Laboratório de Microbiologia. Departamento de Parasitologia Instituto de Ciências Biológicas. Universidade Federal do Amazonas

Recebido: 15/08/06 Aceito: 26/03/07

\section{RESUMO}

Este trabalho apresenta resultados da pesquisa de contaminação dos filtros de condicionadores de ar instalados no setor residencial da cidade de Manaus. A pesquisa foi realizada no âmbito do projeto CAEMA (Condicionadores de Ar, Energia e Meio Ambiente) que consistiu na troca de aparelhos de ar condicionado ineficientes por eficientes na zona urbana da cidade. Dos 500 condicionadores de ar retirados do sistema pelo projeto, foram selecionados 50 filtros $(10 \%)$ para a análise de contaminação biológica, tendo sido identificada uma enorme variedade de agentes prejudiciais à saúde humana, entre bactérias e fungos. A bactéria mais vezes identificada foi a Staphylococcus spe o fungo mais freqüente foi o Penicillium sp. Também foi possível verificar, por meio de entrevistas telefônicas junto a 37 usuários desses equipamentos, a grande incidência de sintomas associados a problemas de insuficiente qualidade de ar nos ambientes residenciais. Circunstâncias que motivaram a oportunidade desta pesquisa também impossibilitaram a coleta das amostras por unidade de volume, com os condicionadores ainda em funcionamento. Esse fato não comprometeu os objetivos da pesquisa, de promover a reflexão sobre os cuidados com a correta limpeza dos condicionadores de ar residenciais.

PALAVRAS-CHAVE: Contaminação, condicionador de ar, qualidade de ar, fungos e bactérias.

\begin{abstract}
This work presents the results of a research about the contamination caused by air conditioners filters that are installed in the residential area in Manaus. The research took place in the scope of CAEMA's project (Conditioning of Air, Energy and Environment), which one consisted in changing inefficient conditional air devices for efficient ones in the urban zone of the city. Amongst 500 air conditioners removed of the system by the project, 50 filters (10\%) were selected for biological contamination analysis, having been identified an enormous variety of agents, like bacteria and fungus, that are harmful for human health. The most identified bacterium was the Staphylococcus sp and the fungus more frequent was the Penicillium sp. Also it was possible to verify, by telephonic interviews with 37 users of these equipments, the great incidence of symptoms associates to the insufficient air quality in residential environments. The circumstances that had motivated the chance of this research, had also disabled that the assemble could be made per volume unit, with the conditioners still working. This fact did not compromise the quality of the work, neither the objectives to promote one reflection about the cares with the correct cleanness of the residential air conditioners.
\end{abstract}

KEYWORDS: Contamination, air conditioning, quality of air, fungus and bacterium. 


\section{INTRODUÇÃO}

Apesar de ainda ser pequena a difusão do conhecimento sobre os efeitos da urbanização no clima das cidades, parece evidente que o crescimento urbano e a industrialização acelerada contribuem para a contaminação da atmosfera. Áreas densamente construídas e urbanizadas sofrem os efeitos do tráfego congestionado de veículos, das construções, dos desmatamentos, das atividades industriais e, também, do uso de condicionadores de ar, indispensáveis para a climatização de ambientes e para o conforto humano, principalmente em cidades tropicais como é o caso da cidade de Manaus, capital do Estado do Amazonas.

As atividades econômicas e a formação desordenada de concentraçōes urbanas, resultando na desigual distribuição populacional, são os principais responsáveis pela perda da qualidade do ar atmosférico nas cidades. Contribui também para o fato a ausência de um planejamento urbano que defina os limites de crescimento da cidade, anomalia que, na realidade, deriva de tradicional prática política clientelista. Sem controle, o crescimento desordenado das cidades torna o espaço urbano cada vez mais concorrido, aumentando a degradação do solo, água e ar e deteriorando a qualidade de vida da população. Conclui-se que, considerando esse quadro, problemas relacionados com a contaminação de ambientes internos são fortemente agravados pelas questôes urbanas, sociais e industriais, tornando preocupantes as condiçôes de saúde ambiental e humana por conseqüência, nas sociedades em desenvolvimento.

Manaus é uma cidade especialmente quente não só devido à sua posição geográfica, como em conseqüência do crescimento e ocupação desordenados que sofreu ao longo de sua história. Possui clima equatorial, quente e úmido e temperatura média de $32^{\circ}$. Com um total de 1.640.690 habitantes distribuídos em $11.401,058 \mathrm{~km}^{2}$, concentra mais de $50 \%$ dos 3.232 .330 habitantes de todo o Estado do Amazonas (IBGE, 2005).

Considerando tais condições climáticas e demográficas, o uso dos aparelhos de ar condicionado é indispensável para a climatização ambiental e, neste caso, o consumo intensificado de energia elétrica está diretamente relacionado com a carga térmica do ambiente e também com as características do aparelho, as características de uso, a condição de limpeza do mesmo e finalmente com a saúde da população.

O homem adapta-se ao desenvolvimento acelerado e busca usufruir desse desenvolvimento, com conforto e, para isso, aprende a controlar as condições do ambiente onde vive e trabalha, tentando, com tecnologia cada vez mais aperfeiçoada, reproduzir o ambiente ideal. No entanto, como bem afirma o arquiteto Sidney Oliveira (2005), condiçôes artificiais demandam "[...] monitoramento e adequaçôes constantes, sob pena de ao invés de consistirem em benefício, caracterizarem-se como fatores de agravamento da qualidade de vida das pessoas".

Parece contraditório que medidas para reduzir o desperdício de energia, tenham causado impactos negativos na qualidade do ar em ambientes fechados. E que, à proporção em que se desenvolveram tecnologias para melhorar o isolamento e reduzir as trocas de ar entre o interior e o exterior, paralelamente, e em consequiência, houve, em função do confinamento do ar em espaços isolados, a degradação de qualidade. Para Lemos (1997), esse é um problema de saúde pública que precisa ser estudado urgentemente e de maneira global e sistemática. Mas isto só será possível, ainda segundo a autora, com a compreensão dos processos industriais, medindo e quantificando os tóxicos (gases, poeiras, vapores...) para conhecer as suas conseqüências sobre a saúde e assim poder controlá-las. No entanto, poucas são as pesquisas sobre poluição atmosférica e muito menos ainda sobre a Qualidade de Ar de Interiores (QAI). Apesar de o ar interno proceder do ar exterior, alguns estudos realizados, tanto em nível internacional quanto nacional, revelaram a existência de contaminantes em proporções bem maiores (até dez vezes maiores) no ambiente interno, o que tem sido atribuído ao fato de os sistemas de ar condicionado "operarem com baixa troca de ar" (Brickus \& Aquino Neto, 1999).

A incorreta limpeza nos filtros e dutos de ar refrigerado propicia o desenvolvimento de fungos, vírus, ácaros, bactérias que podem levar os ocupantes de ambientes climatizados a contraírem doenças respiratórias, infecciosas ou alérgicas. Esse e outros problemas relacionados com a concentração de poluentes em ambientes internos, como liberação de substâncias químicas pela transpiração, ou a dispersão de material tóxico existente em tintas, materiais de limpeza etc, e que são disseminados na atmosfera interior através dos mecanismos de condicionadores de ar, são responsáveis pela poluição em ambientes fechados. O problema levou a Organização Mundial de Saúde a cunhar o termo Síndrome dos Edifícios Doentes (SED), na década de 80, para designar o quadro clínico de quem trabalha nesses ambientes, com um considerável aumento dos casos de alergia e asma, relacionados a uma qualidade de ar interior insuficiente (Vicent \& Pradalier, 1997; Fanger, 2001).

Especificamente, a exposição ao ar contaminado por fungos e seus metabólicos em ambientes interiores, climatizados artificialmente ou não, constitui uma situação comum nos mais variados fragmentos populacionais. $\mathrm{O}$ impacto dessa realidade sobre a saúde humana e a ruptura dos conceitos de qualidade de vida têm preocupado autoridades sociais em todo mundo (Siqueira et al, 2003).

Considerando a preocupação mundial com a qualidade do ar em ambientes climatizados e a ampla e crescente utilização de sistemas de ar condicionado no país em função das condições climáticas, o Ministério da Saúde propôs, através da portaria No 3.523/GM de 28 de agosto de 1998, que sejam determinados padróes de qualidade do ar em ambientes climatizados artificialmente, bem como o seu monitoramento (Gava, 2002).

Mais recentemente têm surgido documentos legais enfocando o problema. A Resolução RE No 9, de 16 de janeiro de 2003, define orientação técnica sobre Qualidade do Ar Interior em ambientes climatizados artificialmente de uso público e coletivo, considerando o interesse sanitário na divulgação do assunto, bem como a preocupação com a saúde, segurança, bem-estar e conforto dos ocupantes dos ambientes climatizados.

O problema, no entanto, não se restringe aos ambientes públicos e coletivos. A contaminação de aparelhos de ar condicionado se verifica mesmo quando se considera o setor residencial. Aqui, importa referir que o trabalhador brasileiro passa, geralmente, 12 horas do seu tempo diário na sua residência e que a exposição aos agentes desencadeadores pode acabar sensibilizando o indivíduo e tornando-o alérgico (van Strien et al, 2004). 
A par dos problemas alérgicos, casos graves de infecções podem resultar da incorreta manutenção dos aparelhos. As fezes de pombos, por exemplo, consideradas a principal fonte de contaminação do Cryptococcus neoformans, quando secas, podem ser aspiradas para dentro do sistema e espalhadas no ambiente refrigerado. Esse fungo é o parasita natural daquelas aves em cujas fezes eles permanecem, possibilitando contágio por períodos de até dois anos. Estudo realizado na cidade de Porto Alegre, em escretas de pombos, confirmou a presença de Cryptococcus neoformans em $100 \%$ das amostras avaliadas e assinala que este fungo pode ser disperso no ar e posteriormente inalado, sendo que "a inalação de grande quantidade dos propágulos poderá causar doença em indivíduos imunocompetentes e imunodeprimidos" (Reolon, Perez \& Mezzari, 2004).

Entretanto, o maior perigo de interiores contaminados é a bactéria Legionella pneumophila ${ }^{1}$, que habita ambientes fechados, "resfriados ou aquecidos por sistemas de ar condicionado que geralmente não proporcionam trocas de ar adequadas para a saúde humana" (Montagner, Paschoalino \& Jardim, 2005). No Brasil, poucos estudos abordam o problema da contaminação de interiores causado por Legionella pneumophila, presente principalmente em ambientes com sistema de resfriamento recirculante. Alguns desses estudos foram realizados em hospitais, razão por que a Legionella pneumophila foi reconhecida pelo Ministério da Saúde como patógeno hospitalar, respondendo por $4 \%$ dos casos fatais de pneumonia hospitalar (ANVISA, 2004).

Estudo realizado por Graudenz \& Dantas (2007) confirma que um único agente pode resultar em epidemias de doenças e exemplifica com a Legionella pneumophila a qual, segundo os autores, se prolifera em torres de resfriamento, podendo infectar após pouco tempo de exposição. $\mathrm{O}$ mesmo estudo faz referência à diferente qualidade do ar em diferentes regiōes do país como Porto Alegre, Manaus e Brasília e considera as variações de temperatura e umidade do sul, o clima seco do Centro-Oeste e as altas temperaturas e umidade da Região Norte. Além disso, argumenta que as construtoras com filiais em todo o território não se adaptam ao tipo de clima local, mantendo o mesmo padrão de edificação.

A associação entre conservação de energia e contaminação dos ambientes internos residenciais surgiu, para esta pesquisa, de forma inesperada, resultando neste trabalho que envolveu o uso de equipamentos com manutenção inadequada e a saúde do usuário. Assim é que a oportunidade do estudo sobre a contaminação dos filtros dos condicionadores de ar consistiu num desdobramento do Projeto CAEMA - Condicionadores de Ar, Energia e Meio Ambiente, realizado pelo grupo de pesquisa do Núcleo Interdisciplinar de Energia, Meio Ambiente e Água (NIEMA) da Universidade Federal do Amazonas.

O projeto CAEMA, financiado pelo Programa de Eficiência Energética da concessionária de energia da Manaus Energia S/A (MESA), efetuou o recolhimento de 500 aparelhos de ar condicionado ineficientes, do setor residencial da cidade de Manaus. A observação da situação de incorreta manutenção e limpeza dos aparelhos recolhidos, os quais se encontravam em pleno funcionamento nas residências dos participantes selecionados, em evidente estado de poluição dos filtros, revelou uma realidade de contaminação generalizada que veio motivar o presente estudo (Figura 1).

A oportunidade de se ter acesso a uma amostra significativa de aparelhos de ar condicionado retirados do setor residencial de Manaus e a importância de investigar as conseqüências da contaminação dos filtros sobre a saúde dos ocupantes dos cômodos refrigerados, conduziram à análise desses filtros, com identificação de possíveis agentes patogênicos aí presentes.

Através deste trabalho buscou-se reunir informações concretas e objetivas acerca dos malefícios de incorretos (ou inexistentes) hábitos de limpeza dos equipamentos. A divulgação dos resultados tem por objetivo contribuir para a adoção de hábitos de limpeza e manutenção que previnam a proliferação de doenças entre os utilizadores do ar condicionado.

\section{COLETA E ANÁLISE DAS AMOSTRAS}

O processo de análise da contaminação dos filtros dos aparelhos de ar condicionado recolhidos pelo Projeto CAEMA foi motivada pela constatação in loco das precárias condições de manutenção e limpeza em que se encontravam esses condicionadores e a realização dessa atividade ficou a cargo do Departamento de Parasitologia do Instituto de Ciências Biológicas da Universidade Federal do Amazonas.

Considerando o universo de 500 condicionadores de ar retirados do sistema, delimitou-se uma amostra de 50 filtros escolhidos aleatoriamente conforme apresentassem aspecto de visível contaminação. Tomando como base a recomendação da Associação Americana de Saúde Pública - APHA - realizou-se a coleta do material existente em um centímetro quadrado de superfície de cada um dos 50 filtros dos aparelhos de ar condicionado, ou seja, a amostra utilizada correspondeu a $10 \%$ do número total de condicionadores recolhidos. A Figura 2 ilustra o momento da coleta. O material foi coletado utilizando $s w a b s^{2}$ esterilizados contendo meio de transporte "Stuart" 3 . Para cada amostra registrou-se o número do selo identificador do aparelho analisado, a fim de estabelecer a relação entre os resultados da análise e o cadastro do consumidor participante no Projeto CAEMA.

\section{Análise e identificação dos agentes patogênicos e implicações da contaminação}

Após a coleta, as amostras foram tratadas e analisadas em laboratório, onde se realizaram as identificações dos agentes patogênicos potencialmente presentes. As mesmas foram ressuspendidas em caldo Brain Heart Infusion (BHI) e a partir deste meio de cultura

\footnotetext{
'A Legionelose - Legionaires Disease, em inglês - foi identificada em 1976, na Filadélfia, nos EUA, durante uma convenção de Legionários, ocasião em que 221 pessoas contraíram a doença, das quais 34 morreram. A bactéria estava alojada nos reservatórios do ar condicionado, tendo encontrado, no pulmão das vítimas, as condiçôes perfeitas para proliferar e causar a infecção.

${ }^{2}$ Cotonetes de cabo comprido e esterilizados

${ }^{3}$ Cada unidade consiste num invólocro estéreo consistindo num swab utilizado para a coleta da amostra e um tubo contendo o meio de transporte no qual o swab é colocado após a coleta.
} 

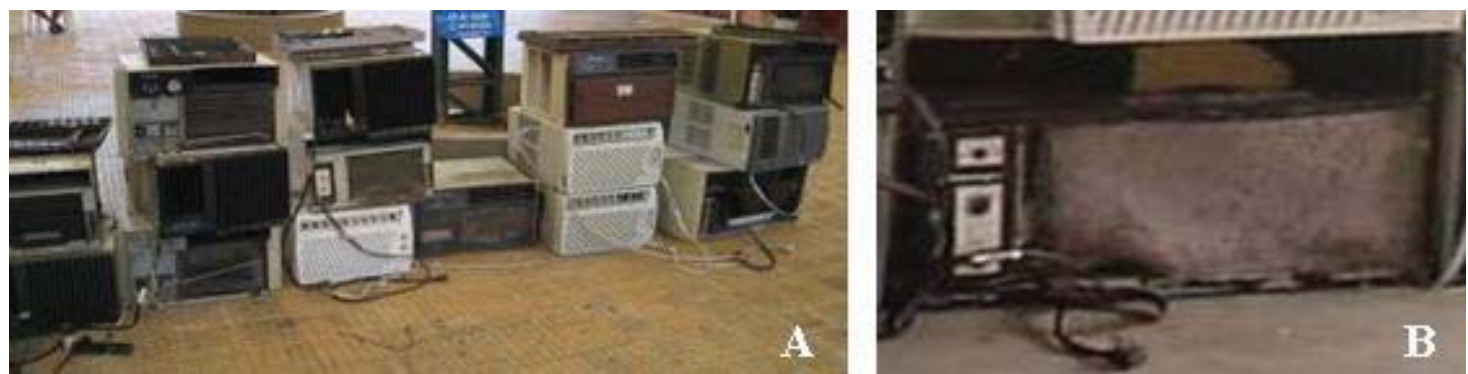

Fonte: Pesquisa CAEMA, 2004

Figura I - Situação de visível contaminação dos aparelhos recolhidos pelo Projeto CAEMA A: Visão geral de uma amostra dos aparelhos; B: Detalhe de um filtro contaminado
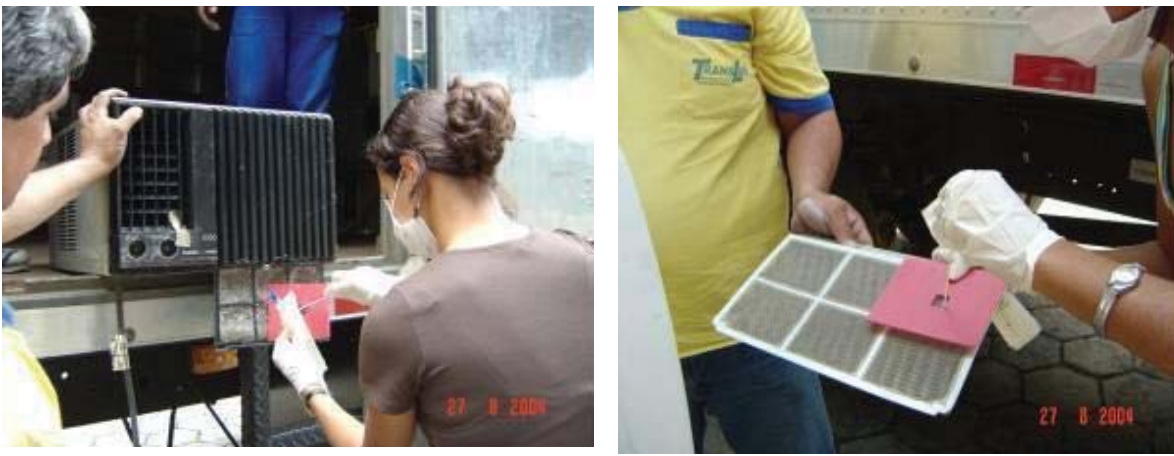

Fonte: Pesquisa CAEMA, 2004

Figura 2 - Coleta das amostras pela Norma APHA

realizaram-se diluições sucessivas até $10^{-4}$. Posteriormente, alíquotas de $0,1 \mathrm{ml}$ foram semeadas nas superfícies dos meios de cultura Plate-Count-Agar, Agar Eosina Azul do Metileno, Agar Manitol e Agar Sabouraud (Sidrim et al, 1999; Lacaz et al, 1991; Domsch et al, 1995).

Na identificação das bactérias, utilizou-se a metodologia de Cowan and Steel's, segundo o Manual de Identificação de Bactérias de Interesse Médico. Este método é internacionalmente reconhecido e padronizado para a identificação de bactérias de importância médica, permitindo diagnosticar todas as bactérias com probabilidade de serem encontradas em laboratórios de saúde pública, na prática médica e veterinária (Barrow \& Feltham, 1993).

A morfologia dos microorganismos foi estudada através do Método de Coloração de Gram e as amostras identificadas foram armazenadas na bacterioteca do Laboratório de Microbiologia do Departamento de Parasitologia do Instituto de Ciências Biológicas.

A metodologia utilizada para identificação dos fungos consistiu, inicialmente, em observações das caracterís- ticas macroscópicas das colônias, tendo sido ressaltados os seguintes aspectos: tamanho da colônia, características dos bordos, textura, relevo e pigmentação. Após esse procedimento as colônias foram repicadas em Agar Sabouraud 4 incubadas à temperatura ambiente durante 5 a 7 dias, retirando-se em seguida fragmentos das culturas para observação das características microscópicas a nível de gênero (Sidrim et al, 1999; Lacaz et al, 1991; Domsch et al, 1995).

No sentido de avaliar possíveis afecções respiratórias, derivadas da contaminação dos filtros sobre os ocupantes do ambiente climatizado, realizou-se uma avaliação das implicações da contaminação por meio de entrevistas telefônicas. Essas entrevistas, aplicadas aos participantes cujos equipamentos foram selecionados para a análise biológica e associados através de selo de identificação, seguiram um roteiro com perguntas semi-abertas para orientar o entrevistador. Desta forma o entrevistado teve maior liberdade para compartilhar suas preocupações sem limitaçôes ou constrangimentos.

O questionário constou de uma parte introdutória, onde se obtiveram informaçóes sobre o entrevistado, características do aparelho trocado e número de utilizadores do(s) cômodo(s) refrigerado(s). A segunda parte do questionário constou de uma sondagem correspondendo a dois momentos: antes e depois da troca dos condicionadores. As questões foram desenvolvidas, considerando possíveis problemas de saúde relacionados à contaminação dos filtros dos aparelhos, e identificados na revisão bibliográfica. Neste sentido, procurou-se reconhecer os problemas respiratórios e/ou alérgicos observados pelos moradores antes da troca dos aparelhos e, por fim, se houve redução dos sintomas após a instalação dos novos condicionadores.

\section{CONTAMINAÇÃO DOS FILTROS}

Verificou-se elevado crescimento de bactérias e fungos nos meios de cultura inoculados com o material biológico coletado nos filtros dos condicionadores de ar. Foram identificados 19 taxa diferentes de bactérias patogênicas e 9 de fungos. No total de 50 amostras, apenas uma (representando $2 \%$ do total) não apresentou crescimento considerável de qualquer tipo de microorganismos;

${ }^{4}$ Esse meio denominado agar Sabouraud Destrose (ASD) ou simplesmente ágar Sabouraud é largamente usado em laboratório por questôes econômicas e por permitir o crescimento da grande maioria de fungos. (ANVISA 2004) 
em 4 amostras (8\%) não se verificou crescimento de nenhum taxa bacteriano em 29 amostras (58\%) não se verificou crescimento de fungos (Tabela 1).

As Figuras 3 e 4 apresentam gráficos que identificam a freqüência de ocorrência dos diferentes taxa de bactérias (a) e fungos (b) identificados nas amostras. Foi possível verificar a bactéria mais vezes identificada, a Staphylococcus sp., com 15 ocorrências; Destacam-se, ainda, as espécies Bordetella parapertussis, Actinomyces sp. e Bacillus anthracis, com ocorrência elevada nas amostras analisadas.

No caso específico desta pesquisa, não foi encontrada a bactéria Legionella pneumophila, responsável por um tipo de pneumonia denominada Legionelose.
Sabe-se, no entanto, que condições climáticas, como alta temperatura e elevada umidade associadas à ausência de correta limpeza dos condicionadores, são consideradas muito favoráveis à proliferação desses e de tantos outros microorganismos (Carmo \& Prado, 1999).

Entre os fungos, o mais freqüente foi Penicillium sp., com 7 ocorrências. Outros fungos, como Cladosporium sp., Rhizopus sp. e Rhodotorula sp., apresentaram-se bastante freqüentes.

\section{IMPLICACCÕES SOBRE OS USUARIOS}

Do total de cinqüenta amostras analisadas, para duas não foi possível identificar o número do selo correspondente (identificação do usuário). Assim sendo, o universo inicial previa um total de 48 participantes a serem contatados no processo de avaliação das implicaçóes da contaminação sobre os usuários de ar condicionado. Entretanto, no período de aplicação da metodologia, verificou-se que mais 11 desses participantes ficaram impossibilitados, por razões diversas, de responder à entrevista, resultando na realização de 37 entrevistas. Esse número, embora pequeno em valores absolutos, é representativo se for considerado que cobre $74 \%$ do universo total de participantes incluídos na amostra.

$\mathrm{Na}$ primeira sondagem, foi averiguada a incidência de problemas

Tabela I - Resultados obtidos na identificação de bactérias e fungos patogênicos

\begin{tabular}{|c|c|c|c|c|}
\hline Amostra & No Selo & Bactgérias identificadas & $\begin{array}{l}\text { Quantificação de bactérias } \\
\left(\mathrm{UFC} / \mathrm{cm}^{2}\right)\end{array}$ & $\begin{array}{c}\text { Fungos } \\
\text { identificados }\end{array}$ \\
\hline 01 & 337 & Bacillus anthracis & 200.000 & Penicillium sp. \\
\hline 02 & 378 & Bordetella parapertussis & 100.000 & AUSENTE \\
\hline 03 & 135 & Actinomyces sp & Menor que 1.000 & Penicillium sp. \\
\hline 04 & 213 & Staphylococcus sp. & 70.000 & AUSENTE \\
\hline 05 & 411 & Staphylococcus sp. & 10.000 & Dermatiáceo, Paecilomyces sp. \\
\hline 06 & 457 & Campylobacter sp. & 20.000 & Penicillium sp. \\
\hline 07 & 487 & Bacillus anthracis & 40.000 & AUSENTE \\
\hline 08 & 467 & Sthaphylococcus aureus & 20.000 & Penicillium sp. \\
\hline 09 & 499 & Shigella dysenteriae & 300.000 & AUSENTE \\
\hline 10 & 445 & Bacillus sp. & 10.000 & AUSENTE \\
\hline 11 & 062 & AUSENTE & 0 & Cladosporium \\
\hline 12 & 218 & Bacillus sp. & 30.000 & AUSENTE \\
\hline 13 & 111 & Staphylococcus epidermis & 20.000 & Rhizopus sp. \\
\hline 14 & 112 & Bordetella parapertussis & 100.000 & AUSENTE \\
\hline 15 & 486 & AUSENTE & 0 & Cladosporium sp. \\
\hline 16 & * & Bordetella parapertussis & 7.600 .000 & AUSENTE \\
\hline 17 & 043 & Bacillus sp. & 2.600 .000 & AUSENTE \\
\hline 18 & 286 & $\begin{array}{c}\text { Streptobacillus sp., Bordetella } \\
\text { parapertussis }\end{array}$ & 40.000 & AUSENTE \\
\hline 19 & 074 & Klebsiella sp. & Menor que 1.000 & Aspergillus sp. \\
\hline 20 & * & Micrococcus & Menor que 1.000 & AUSENTE \\
\hline 21 & 526 & Staphylococcus epidermidis & 10.000 & AUSENTE \\
\hline 22 & 513 & Streptomyces sp. & 200.000 & Penicillium sp. \\
\hline 23 & 052 & Staphylococcus aureus & 400.000 & AUSENTE \\
\hline 24 & 325 & Escherichia coli, Actinomyces sp. & Menor que 1.000 & Cladosporium sp. \\
\hline 25 & 061 & Staphylococcus sp. & 30.000 & AUSENTE \\
\hline
\end{tabular}


Tabela I - Resultados obtidos na identificação de bactérias e fungos patogênicos (continuação)

\begin{tabular}{|c|c|c|c|c|}
\hline Amostra & No Selo & Bactérias identificadas & $\begin{array}{l}\text { Quantificação de bactérias } \\
\left(\mathrm{UFC} / \mathrm{cm}^{2}\right)\end{array}$ & Fungos identifiados \\
\hline 26 & 239 & Staphylococcus sp. & 100.000 & Penicillium sp. \\
\hline 27 & 399 & Staphylococcus sp. & 3.240 .000 & AUSENTE \\
\hline 28 & 379 & Staphylococcus sp. & 800.000 & Penicillium sp. \\
\hline 29 & 098 & $\begin{array}{l}\text { Staphylococcus sp., } \\
\text { Bordetella parapertussis }\end{array}$ & 4.280 .000 & AUSENTE \\
\hline 30 & 099 & $\begin{array}{c}\text { Corynebacterium } \\
\text { pseudodiphecterium }\end{array}$ & 1.100 .000 & Rhodotorula sp. \\
\hline 31 & 130 & Staphylococcus sp. & 30.000 & AUSENTE \\
\hline 32 & 278 & $\begin{array}{l}\text { Enterobacter, } \\
\text { Actinomyces sp. }\end{array}$ & Menor que 1.000 & AUSENTE \\
\hline 33 & 134 & Staphylococcus sp. & 3.500 .000 & AUSENTE \\
\hline 34 & 079 & Staphylococcus sp. & 80.000 & Rhizopus sp. \\
\hline 35 & 398 & $\begin{array}{c}\text { Staphylococcus sp., } \\
\text { Acinetobacter calcoaceticus }\end{array}$ & 2.200 .000 & AUSENTE \\
\hline 36 & 145 & $\begin{array}{l}\text { Bordetella parapertussis, } \\
\text { Actinomyces sp. }\end{array}$ & 1.110 .000 & Rhodotorula sp. \\
\hline 37 & 144 & $\begin{array}{l}\text { Staphylococcus sp., Bacillus } \\
\text { anthracis, Actinomyces sp. }\end{array}$ & 8.500 .000 & Rhodotorula sp. \\
\hline 38 & 174 & Bordetella prapertussis & 10.000 & Mucorsp. \\
\hline 39 & 232 & $\begin{array}{l}\text { Staphylococcus sp., Bacillus } \\
\text { saaroliticus, Actinomyces sp. }\end{array}$ & 1.500 .000 & Rhodotorula sp. \\
\hline 40 & 279 & $\begin{array}{l}\text { Staphylococcus sp., } \\
\text { Campylobacter sp. }\end{array}$ & 52.800 .000 & Mucorsp. \\
\hline 41 & 251 & $\begin{array}{c}\text { Staphylococcus sp., Bordetella } \\
\text { parapertussis }\end{array}$ & 600.000 & AUSENTE \\
\hline 42 & 246 & AUSENTE & 0 & Cladosporium sp. \\
\hline 43 & 500 & $\begin{array}{l}\text { Campylobacter sp., } \\
\text { Actinomyces sp. }\end{array}$ & 8.300 .000 & Acremonium sp. \\
\hline 44 & 528 & Bordetella parapertussis & 130.000 & AUSENTE \\
\hline 45 & 475 & $\begin{array}{l}\text { Bordetella parapertussis, } \\
\text { Nocardia sp. }\end{array}$ & 313.600 .000 & Rhizopus sp. \\
\hline 46 & 156 & Bacillus anthracis & 64.000 .000 & AUSENTE \\
\hline 47 & 437 & Staphylococcus aureus & 20.000 & AUSENTE \\
\hline 48 & 384 & $\begin{array}{c}\text { Brochotix, Acinetobacter } \\
\text { calcoaceticus }\end{array}$ & 129.600 .000 & Rhizopus sp. \\
\hline 49 & 202 & Bordetella parapertussis & 28.500 .000 & AUSENTE \\
\hline 50 & 102 & AUSENTE & 0 & AUSENTE \\
\hline
\end{tabular}

* Número do selo não identificado

Fonte: Pesquisa CAEMA, 2004 
respiratórios e/ ou alérgicos entre os utilizadores do aparelho de ar condicionado, alvo da pesquisa. Verificou-se que $51 \%$ dos entrevistados testemunharam pelo menos um sintoma relacionado a esse tipo de doença. A figura 5 apresenta a lista de sintomas indicados pelos entrevistados, com a respectiva menção ao número de vezes em que este foi referido.

Dentre os problemas classificados na categoria «Outros», incluem-se: coceira no nariz, enxaqueca, fadigas, febre, irritações na garganta e nariz, secura na garganta, resfriados, secreção no nariz, sinusite e tosses alérgicas.

Perguntou-se, ainda, a todos os entrevistados que identificaram a ocorrência de sintoma(s), se, após a troca do aparelho antigo pelo aparelho novo (o qual se pressupóe menos contaminado), haviam verificado redução dos sintomas: $74 \%$ responderam sim contra $26 \%$ que não perceberam alterações de sintomas.

\section{ANÁLISE DOS RESULTADOS OBTIDOS}

Os resultados obtidos vieram confirmar o fato de que os aparelhos de ar condicionado recolhidos no âmbito do Projeto CAEMA se encontravam, de modo geral, contaminados. De fato, apenas um dos cinqüenta aparelhos amostrados se apresentou livre de contaminação de origem bacteriológica ou fúngica. Convém, entretanto, referir que vários outros tipos de contaminação podem existir fora do âmbito do presente trabalho, seja de origem biológica (vírus, protozoários, pólen, etc.) ou química.

Quase todos os agentes identificados apresentam conseqüências negativas para a saúde humana - fato relacionado à própria metodologia utilizada, especialmente no caso das bactérias - estando associados a quadro clínico que pode, em certos casos, atingir elevada gravidade, conforme demonstra a Tabela 2 .

$\mathrm{Na}$ maioria dos casos, as afecções podem ser de origem respiratória, agravando a periculosidade da presença desses agentes em filtros de aparelhos condicionadores de ar. Na Tabela 3 a mesma metodologia foi utilizada relacionando-se o quadro clínico aos

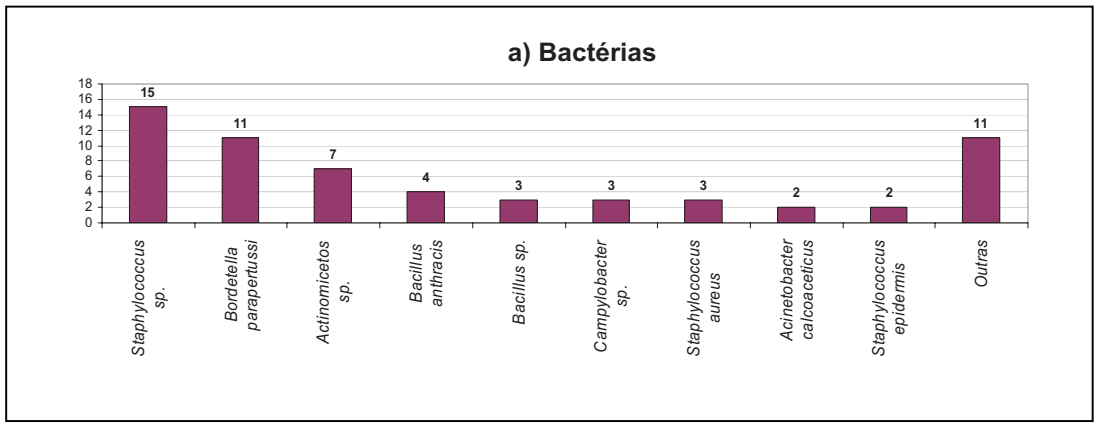

Fonte: Pesquisa CAEMA, 2004

Figura 3 - Ocorrência de bactérias ${ }^{5}$

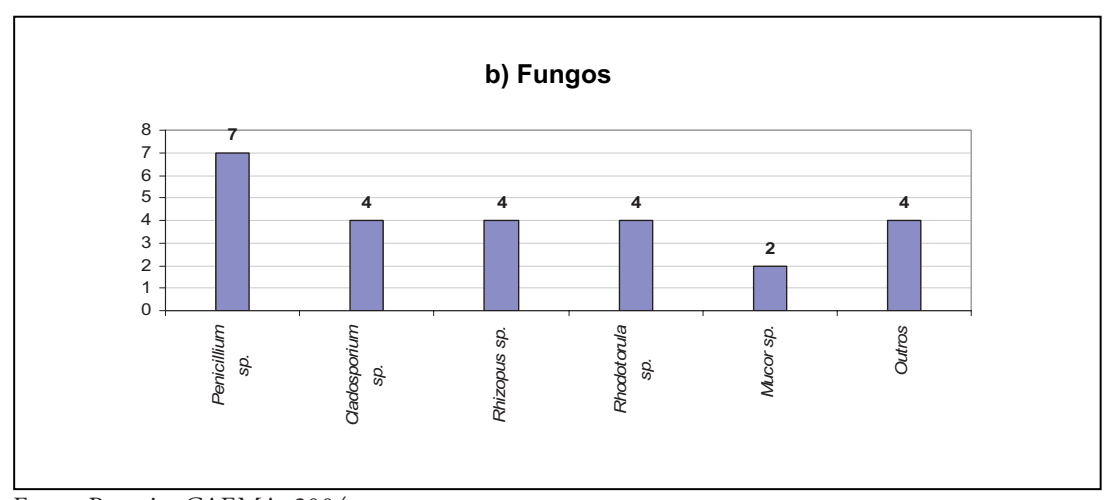

Fonte: Pesquisa CAEMA, 2004

Figura 4 - Ocorrência de Fungos ${ }^{6}$

Número total

absoluto

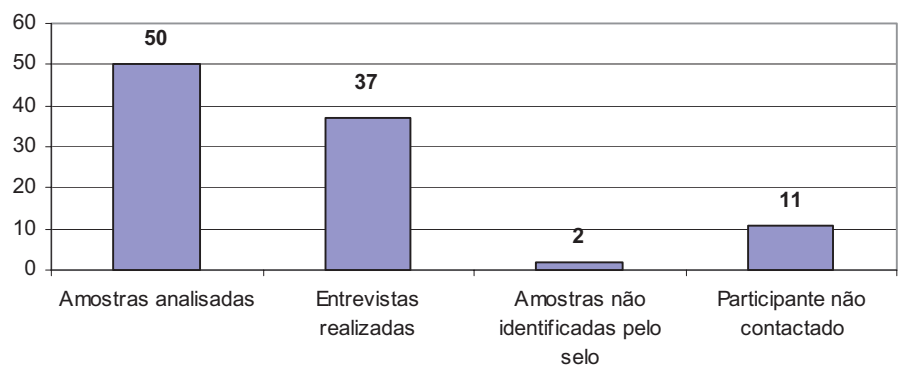

Fonte: Pesquisa CAEMA, 2004

Figura 5 - Sintomas de problemas respiratórios ou alérgicos referidos pelos entrevistados

fungos associados às amostras, conforme demonstra a Tabela 3.

A elevada presença, nos filtros analisados, de agentes como Bordetela parapertussis, Staphylococcus e Actinomyces, entre outros com elevado grau de patogenicidade, indicou uma situação de potencial risco para a saúde. Entretanto, convém notar que, apesar da presença identificada dos agentes referidos nos filtros dos condicionadores de ar analisados, é impossível afirmar, com certeza, que esses mesmos agentes possam estar reduzindo, de forma significativa, a qualidade do ar interior do cômodo refrigerado e, menos ainda, que o fato defina a condição de enfermidade de seus ocupantes. Isto porque o desen- 
Tabela 2 - Bactérias identificadas e associadas às amostras

\begin{tabular}{|c|c|c|}
\hline Agente identificado & Quadro clínico associado & $\begin{array}{l}\text { No de selo } \\
\text { onde foram } \\
\text { encontrados }\end{array}$ \\
\hline \multicolumn{3}{|c|}{ Bactérias } \\
\hline Bordetella parapertussis & Causa uma doença semelhante à coqueluche & $\begin{array}{l}378,112,286,098 \\
174,251,528,475 \\
202,145^{*}\end{array}$ \\
\hline Campylobacter & Diarréia & $457,500,279$ \\
\hline Escherichia coli & Infecçōes urinárias, doenças diarréicas; Meningite & 325 \\
\hline Shigella & Febre, dores abdominais, diarréia e pode ser contagiosa & 499 \\
\hline Klebsiella & Infecçōes localizadas (próstata, pulmões, meninges e ossos) & 47 \\
\hline Acinetobacter & Um dos agentes patogênicos causador da pneumonia & 398,384 \\
\hline Bacillus anthracis & $\begin{array}{l}\text { Responsável pelo carbúnculo, doença infecto-contagiosa } \\
\text { conhecida vulgarmente em nosso país por "Peste da } \\
\text { Manqueira" ou "Mal de Ano" }\end{array}$ & $337,487,144,156$ \\
\hline Actinomyces sp. & Lesōes cerebrais e abdominais; Cáries dentárias & $\begin{array}{c}135,278,145,144 \\
232,500,325\end{array}$ \\
\hline \multirow[t]{6}{*}{ Sthaphylococcus } & Infecções urinárias; & $213,411,061,239$, \\
\hline & Pneumonia e Meningite & $399,379,098,130$ \\
\hline & Síndrome do Choque Tóxico (nas mulheres) & $\begin{array}{l}134,079,398,144 \\
232,279,251\end{array}$ \\
\hline & Furúnculos, doenças na pele, nariz e garganta & \\
\hline & $\begin{array}{c}\text { Do tipo aureus pode-se causar: meningite e } \\
\text { infecçôes pulmonares }\end{array}$ & $467,052,437$ \\
\hline & Do tipo epidermis pode causar doenças na pele & 111,526 \\
\hline Corynebacterium & $\begin{array}{l}\text { Doenças respiratórias;- Eristrasma (infecção superficial da pele } \\
\text { da axila e região púbica) }\end{array}$ & 99 \\
\hline
\end{tabular}

Tabela 3 - Fungos identificados e associados às amostras.

\begin{tabular}{|c|c|c|}
\hline \multicolumn{3}{|c|}{ Fungos } \\
\hline Agente identificado & Quadro clínico associado & $\begin{array}{l}\text { No de selo } \\
\text { onde foram } \\
\text { encontrados }\end{array}$ \\
\hline Penicillium sp. & Inofensivo ao homem & $\begin{array}{l}337,135,457,467 \\
513,239,379\end{array}$ \\
\hline $\begin{array}{l}\text { Dermatiaceo } \\
\text { Paecilomyces sp. }\end{array}$ & Causa as chamadas micoses oportunistas & 411 \\
\hline Cladosporium sp. & Inofensivo ao homem & $062,486,246,325$ \\
\hline $\begin{array}{l}\text { Rhizopus sp., } \\
\text { Mucor sp }\end{array}$ & $\begin{array}{l}\text { Fungos que se encontram na natureza e podem ser adquiridos } \\
\text { por aspiração dos esporos }\end{array}$ & $\begin{array}{l}475,384,111,079 \\
174,279\end{array}$ \\
\hline Aspergillus sp. & $\begin{array}{c}\text { O fungo pode atingir as cavernas pós-tuberculósicas, em } \\
\text { pessoas que apresentem lesões que permaneceram após a cura } \\
\text { da tuberculose. O paciente apresenta tosse, } \\
\text { expectoração e hemoptise }\end{array}$ & 74 \\
\hline Rhodotorula sp. & $\begin{array}{c}\text { Infecção pulmonar, podendo acometer o sistema nervoso } \\
\text { central, vísceras, pulmões, ossos, regiōes } \\
\text { cutâneas e mucocutaneas }\end{array}$ & $099,145,144,232$ \\
\hline
\end{tabular}


volvimento do quadro clínico adverso se encontra intimamente dependente das características de cada indivíduo, sua resistência, condição inicial de saúde, grau de exposição, idade, predisposição, etc. Além disso, alguns agentes podem ficar confinados ao filtro, sem se disseminar no ambiente.

Ainda assim, é de notar que os resultados obtidos pelas entrevistas telefônicas indicam elevada ocorrência de sintomas reconhecidamente associados à contaminação do ar interior, confirmando a realidade, amplamente descrita na bibliografia, de que a freqüência de problemas desse tipo está crescendo, principalmente entre utilizadores de ambientes refrigerados. Por outro lado, os resultados também sustentam a idéia de que cidades, como Manaus, apresentam condições ótimas para proliferação de muitos agentes responsáveis por problemas respiratórios, aumentando a incidência de sintomas sobre a população.

Apesar de a contaminação dos filtros dos aparelhos por bactérias, evidenciada neste trabalho, estar associada em alguns casos a quadros clínicos graves, observa-se que o enfoque da legislação pertinente se encontra majoritariamente centrado na contaminação fúngica. A Resolução RE no 9, de 16 de janeiro de 2003, por exemplo, estabelece padrōes exclusivamente para fungos, e ainda determina que "é inaceitável a presença de fungos patogênicos e toxigênicos"; Entretanto, nada refere com relação às bactérias patogênicas e toxigênicas, as quais, como se verificou, em alguns casos, ocorrem mesmo quando da ausência de contaminação fúngica (fato verificado para 27 das 50 amostras analisadas, ou seja, 54\% do total).

No entanto, se a citada Resolução for cumprida, principalmente no que tange ao item 3.4 que trata das taxas de renovação do $\mathrm{ar}^{7}$, muitos dos problemas de poluição e contaminação interna seriam minimizados ou mesmo eliminados, pois reduziriam os níveis de concentração dos poluentes no ar dos interiores. Além de melhorar a ventilação dos ambientes, a preocupação com a limpeza dos filtros e dutos dos condicionadores de ar é uma providência que ajuda a combater doenças respiratórias, alérgicas e infecciosas na medida em que evita o desenvolvimento de microorganismos, potencialmente responsáveis por esses males.

É indispensável esclarecer que a RE no 09 refere-se, preferencialmente a sistemas de condicionamento central os quais apresentam dutos, bandejas de água de condensação e torres de resfriamento. No entanto, a poluição e a má qualidade do ar interior nas residências, devidos à falta de cuidados higiênicos com os equipamentos de refrigeração, começam a se constituir em fontes muito importantes de problemas de saúde.

\section{CONCLUSÕES E RECOMENDAÇỖES}

Com a realização do presente trabalho foi possível avaliar uma elevada contaminação dos aparelhos de ar condicionado no setor residencial de Manaus. A partir da observação empírica inicial de que a maioria dos filtros dos 500 condicionadores trocados se encontrava em degradado estado de limpeza e manutenção, foi possível, em laboratório, identificar em 50 amostras coletadas uma enorme variedade de microorganismos.

Os resultados observados em laboratório obtiveram confirmação na realidade testemunhada pelos usuários dos aparelhos analisados, conforme se constatou nas entrevistas realizadas. Verificou-se grande incidência de sintomas associados a problemas de insuficiente qualidade de ar interior, além de uma percepção, quase generalizada, de que, após a troca do aparelho contaminado por outro novo (que se pressupóe menos contaminado), os sintomas verificaram redução de persistência e até mesmo teriam cessado de ocorrer.

Ao analisar as principais dificuldades verificadas durante a realização do trabalho, e para otimizar a aplicação futura da metodologia, algumas recomendaçôes merecem ser consideradas. Em primeiro lugar, reitera-se a importância de buscar a realização da coleta das amostras in loco, com o aparelho de ar condicionado ainda funcionando. A adoção desse procedimento impedirá alguma possível contaminação dos filtros após a retirada dos condicionadores, além de garantir a integridade das comunidades microbióticas presentes, em situações ecológicas reais, relativamente a fatores como a umidade, obscuridade, ventilação, etc.

No presente trabalho, as circunstâncias que motivaram a oportunidade da pesquisa, em momento posterior à retirada dos aparelhos das residências, não permitiu que a coleta fosse realizada dessa forma. Outro aspecto que se traduziu numa dificuldade de análise dos resultados, ao abrigo da legislação existente, foi a metodologia de coleta utilizada. A Resolução RE no 9, de 16 de janeiro de 2003 refere padróes máximos com relação à contaminação fúngica, os quais não puderam ser avaliados por se referirem à concentração de organismos por volume de ar. Ao invés, neste trabalho, chegou-se a valores de contaminação por unidade de área. Assim sendo, sugere-se a padronização da metodologia seguindo a norma existente, de forma a permitir futuras comparações.

Apesar das dificuldades encontradas, inerentes ao pioneirismo da proposta, é possível concluir que se reuniram informaçôes muito importantes acerca dos riscos que correm os utilizadores de condicionadores de ar na ausência de limpeza dos filtros, pela exposição a uma série de agentes microbiológicos. Estes podem, em determinadas situações, ser responsáveis por variadas doenças, algumas das quais com elevada gravidade, como é o caso da pneumonia e outras infecçôes respiratórias.

Daqui se pode concluir sobre a importância de divulgar os resultados obtidos de forma ampla à sociedade, contribuindo para a sensibilização dos utilizadores de condicionadores de ar acerca das conseqüências, para a saúde, de sua incorreta manutenção e limpeza. Ao mesmo tempo, é importante o conhecimento, pelos ocupantes dos ambientes climatizados artificialmente, das medidas que devem ser tomadas para evitar o aumento das concentrações de agentes químicos e biológicos. $\mathrm{O}$ morador esclarecido e os ocupantes de prédios públicos poderão assumir um controle maior sobre a manutenção dos equipamentos e limpeza dos sistemas de circulação do ar nos interiores, além de seguir padróes de ventilação, práticas importantes para reduzir o potencial de contaminação química e biológica.

\footnotetext{
"A taxa de renovação do Ar adequada de ambientes climatizados será, no mínimo, de $27 \mathrm{~m}^{3} /$ hora / pessoa, exceto no caso específico de ambientes com alta rotatividade de pessoas. Nestes casos a Taxa de Renovação do Ar mínima será de $17 \mathrm{~m}^{3}$ / hora / pessoa, não sendo admitido em qualquer situação que os ambientes possuam uma concentraçăo de CO maior ou igual a estabelecida no Item IV - 2.1, desta orientação técnica." (Oliveira, 2005)
} 


\section{REFERÊNCIAS}

BARROW, G. I., FELTHAM, R.K.A. Manual for identification of medical bacterial. 3.ed. Cambridge: University, 165p. 1993.

BRASIL, Ministério da Saúde. ANVISA - Agência Nacional de Vigilância Sanitária. Resoluçãa publicação de Orientação Técnica elaborada por Grupo Técnico Assessor, sobre Padrōes Referenciais de Qualidade do Ar Interior, em ambientes climatizados artificialmente de uso público e coletivo. Diário Oficial da União; Poder Executivo, de 20 de janeiro de 2003.

BRASIL, Ministério da Saúde. ANVISA - Agência Nacional de Vigilância Sanitária. Aspectos de Segurança no Ambiente Hospitalar. Disponível em http://www.opas.org.br/gentequefazsaude/bvsde/ bvsacd/cd49/seguro.pdf. Acesso em 10.04.2006

BRICKUS, L.S.R.; AQUINO NETO, F. R. A qualidade do ar de interiores e a Quimica. LADETEC

- Instituto de Química. Universidade Federal do Rio de Janeiro. CT-Bloco A. Rio de Janeiro: Química Nova, 22 (1) 1999.

CARMO, A. T.; PRADO, R.T. A. Qualidade do ar interno. Texto técnico. Escola Politécnica da Universidade de São Paulo - EPUSP. Departamento de Engenharia de Construção Civil ISSN 1413-0386. TT/PCC/23. São Paulo, 35p. 1999.

DOMSCH, K.H., GAMS, W. \& ANDERSON, T.H. Compendium of soil fungi. IHW-Verlag, Alemanha. 1995.

FANGER, P. O. Human requirements in future air-conditioned environments. International Journal of Refrigeration; Vol. 24; Elsevier; 2001.
GAVA, M. A. Desempenho nos Diferentes Meios de Cultura Utilizados na Avaliação de Fungos presentes em ambientes de produção de alimentos. $65 \mathrm{f}$. Dissertação (Mestrado em Ciências: Microbiologia Agrícola). Escola Superior de Agricultura. Universidade de São Paulo, São Paulo.

GRAUDENZ, G. S.; DANTAS, E. Poluição dos ambientes interiores: doenças e sintomas relacionados às edificaçôes. Revista Brasileira de Medicina. Ano 2, $\mathrm{N}^{\circ} 1$. Fev/2007.

IBGE. Banco de Dados 2005. Disponível em: www.ibge.gov.br. Acesso em 10.04.2006.

LACAZ, C. S. et al. Micologia médica: Fungos, algas e actinomicetos de interesse médico. 8 Edição, Editora Guanabara Koogan, São Paulo, 1991.

LEMOS, E. T. Poluição Interior e Abordagem ao Síndroma dos Edifícios Doentes. In: Educação Ciência e Tecnologia. Millenium on line. No 7 , Ambiente. Julho de 1997.

MONTAGNER, C.C.; PASCHOALINO, M. P.; JARDIM, W. F. Aplicação da fotocatálise heterogênea na desinfecção de água e ar. Caderno Temático, vol. 4. Universidade Estadual de Campinas - UNICAMP. Instituto de Química. Laboratório de Química Ambiental. Fevereiro de 2005.

OLIVEIRA, S. Qualidade do ar de interiores. In: Arquitetura e Design, Setembro de 2005. Disponível em www.arquitetura.com.br. Acesso em 18.04.2006.

REOLON, A.; PEREZ, L. R. R.; MEZZARI, A. Prevalência de Cryptococcus neoformans nos pombos urbanos da cidade de Porto Alegre, Rio Grande do Sul. J. Brás. Patol. Méd. Lab., vol. 40, no.5, p. 293-298. ISSN 1676-2444, Out. 2004.

SIDRIM, J. J. C.; MOREIRA, J. L. B. Fundamentos Clínicos e Laboratoriais da Micologia Médica.
Vol. Único. Editora: Guanabara Koogan. Rio de Janeiro, RJ, 1999.

SIQUEIRA, L. F. G.; SILVEIRA, M. J.; FERREIRA, L. A . P. Gestão Ambiental das Edificaçôes. Sociedade Brasileira de Meio Ambiente e Controle de Qualidade do Ar de Interiores - BRASINDOOR. Artigo do mês de fevereiro de 2003.Disponível em: <http://www.brasindoor.com.br/prog artigo php>. Acesso em: 03 dezembro 2004.

VAN STRIEN, R.T. et al. The influence of air conditioning, humidity temperature and other household characteristics on mite allergen concentrations in the northeast United States. Allergy; Vol. 59; Blackwell Munksgaard; Reino Unido; novembro; 2004

VICENT, D.; PRADALIER, A. Impact sanitaire de la climatisation: qu'en est-il du syndrome des "bâtiments malsains»? Ver. Méd. Interne; Vol. 18; Elsevier; Paris; março; 1997.

Endereço para correspondência:

\section{Elizabeth Ferreira Cartaxo \\ Universidade Federal do \\ Amazonas - UFAM \\ Faculdade de Tecnologia \\ Campus Universitário - Coroado \\ 69077-000 Manaus - AM - Brasil \\ Teleax: (92) 36474469 \\ E-mail: ecartaxo@ufam.edu.br}

